\title{
Physical activity counselling among GPs: a qualitative study from Thailand
}

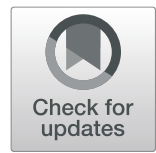

Apichai Wattanapisit ${ }^{1,2^{*}}$, Sanhapan Thanamee ${ }^{3}$ and Sunton Wongsiri ${ }^{4}$

\begin{abstract}
Background: Physical activity (PA) counselling is an intervention to promote PA among patients in primary care, yet it remains limited in this clinical setting. This study aimed to explore PA counselling practices among general practitioners (GPs), as well as barriers to and recommendations for improving PA counselling.

Methods: This qualitative study employed a descriptive approach. Data were collected by in-depth interviews and analysed by thematic analysis. The study was conducted in district hospitals in Nakhon Si Thammarat, Thailand, from February 2017 to February 2018. The study participants were GPs who worked at district hospitals.

Results: Seventeen GPs ( 6 males and 11 females, mean age $29.8 \pm 3.4$ years) from 6 district hospitals were interviewed. Their clinical experience ranged from 2 to 12 years (mean $4.7 \pm 2.9$ ). The GPs saw 30-80 outpatients/ day (mean $56.2 \pm 14.1$ ) and spent $1-8$ min (mean $3.8 \pm 1.8$ ) with each patient. They emphasised PA in patients with poorly controlled non-communicable diseases (NCDs) using the word 'exercise' in the Thai language as well as discussing time and frequency of exercise. PA was considered a non-pharmacological treatment in the management of NCDs, which improved patient health and quality of life. Barriers to PA counselling among GPs included time constraints, insufficient knowledge, and lack of opportunities to follow-up previously counselled patients. GPs suggested that training in PA counselling was required.

Conclusions: GPs concurred that PA counselling is essential in the treatment of NCDs. Physicians' recommendations to improve the quality of PA counselling in primary care include 3 Ts: training in PA counselling, tools for prescribing PA, and teams of healthcare professionals. Implementing use of written PA prescriptions may encourage patients to increase PA. Multidisciplinary teams should be developed to support PA counselling in the clinical setting. Further studies should focus on appropriate techniques to implement PA counselling and overcome existing barriers.
\end{abstract}

Keywords: Counselling, General practitioner, Physical activity, Physician, Primary care

\section{Background}

The World Health Organization (WHO) reports that non-communicable diseases (NCDs) are responsible for $63 \%$ of all deaths worldwide [1]. Around three-quarters of heart disease, stroke and type 2 diabetes, as well as $40 \%$ of cancer could be prevented by eliminating major risk factors, including physical inactivity, unhealthy diet, tobacco use and alcohol abuse [2]. Specifically, physical inactivity causes more than a million deaths each year and contributes to billions of dollars in direct and

\footnotetext{
* Correspondence: apichai.wa@wu.ac.th

'School of Medicine, Walailak University, Thasala, Nakhon Si Thammarat 80161, Thailand

2Walailak University Hospital, Thasala, Nakhon Si Thammarat 80161, Thailand Full list of author information is available at the end of the article
}

indirect economic losses [3, 4]. Accordingly, the WHO prioritises increasing physical activity (PA) among the world population as a global target [5]. Global and national recommendations regarding PA are widely provided to promote and facilitate exercise guidance and healthier lifestyles [6, 7].

PA counselling in clinical settings is a promising intervention to promote PA since this approach increases exercise levels, physical functions and quality of life [811]. A systematic review estimates that PA promotion in primary care can change 1 out of 12 sedentary patients to become physically active [12]. Compared to smoking cession advice, physicians need to counsel 35-120 smokers to change 1 smoker becomes a non-smoker

(c) The Author(s). 2019 Open Access This article is distributed under the terms of the Creative Commons Attribution 4.0 International License (http://creativecommons.org/licenses/by/4.0/), which permits unrestricted use, distribution, and 
[13]. Hence, PA promotion is thus an effective approach and remains among the best interventions capable of increasing exercise [14-16]. Moreover, physicians are perceived as powerful motivators armed with credible and reliable information regarding PA [17, 18]. Encounters between physicians and patients provide chances for PA counselling and lifestyle discussions [19, 20]. However, barriers to providing PA counselling in clinical practice, such as time constraints and lack of knowledge or training, remains a challenge [21].

Physicians are expected to possess competence in offering PA counselling while preventing, treating and managing diseases [22]. In Thailand, physician competence in health promotion issues is assessed by criteria set forth by national medical licencing requirements [23]. However, PA counselling is not specified as a compulsory topic in medical education curricula. To the best of our knowledge, PA counselling has not received adequate attention by Thai physicians and researchers. According to the Thai healthcare system, general practitioners (GPs) usually refer to medical graduates or nonspecialised physicians. GPs can work in any primary care settings such as, public hospitals, private hospitals, and private clinics. The majority of GPs are mandated to work at general and district hospitals during their first three years after graduation. Then, they have an option to continue the GP status at district hospitals or participate in specialty training. Most district hospitals in Thailand provide hospital-based primary care services, NCD clinics, and inpatient services. Therefore, GPs are expected to run those services. All Thai people are guaranteed access to free healthcare services in the public sectors under the universal health coverage system, including, the Universal Coverage Scheme (75\% of the Thai population), the Social Security Scheme (16\%), and the Civil Servant Medical Benefit Scheme (9\%) [24].

This study therefore aimed to explore PA counselling practices among Thai GPs and barriers to such clinical intervention. This study also obtained practitioners' viewpoints for improving PA counselling practices in primary care.

\section{Methods}

\section{Study design and context}

This qualitative study employed a descriptive approach to explore a deeper understanding of PA counselling, barriers to such practices, and recommendations to improve counselling in the primary care setting. Semistructured in-depth interviews (IDIs) were conducted in Nakhon Si Thammarat province, the most populated province in southern Thailand from February 2017 to February 2018. GPs, who worked at district hospitals, were invited to participate in this study.

\section{Sampling and recruitment}

We recruited both male and female GPs with more than 1 year of clinical experience by purposive sampling. We excluded physicians who were certified specialists or in specialist training. We also applied snowball sampling to reach participants with characteristics of interest through their social networks [25]. We made phone calls to eligible GPs or met them at their clinics to ask their verbal permission to participate in the study. Subsequently, we scheduled interviews with participants via telephone and social networks and then conducted all IDIs at their places of work.

\section{Data collection}

A family physician (AW), trained and experienced in qualitative interviewing, conducted all IDIs in Thai. The interviewer provided each participant with an information sheet before the interview. Participants were asked to complete a short questionnaire about personal information and characteristics of outpatients seen in practice. The interviewer interviewed the participants using the interview guide (Table 1) with probing questions to explore the meaning of answers. IDIs were recorded with a digital audio recorder with permission of participants. Each IDI took 30-60 min. We did not identify the initial target sample size. The number of IDIs depended on data saturation, which new data repeat what was revealed in previous data [26].

\section{Data analysis}

All audio-recorded files were transcribed verbatim. We managed the transcripts using Microsoft Word (the Office 365 University package, Microsoft Inc., Redmond, WA, USA) and printed documents (hard copies). Participants' names were coded to ensure confidentiality and anonymity. We analysed data using the deductive thematic approach [27, 28]. First, two researchers (AW and ST), both trained and experienced in qualitative methods, read and reread the first transcript to familiarise themselves with the data obtained. The researchers then independently performed initial coding, where codes were assigned throughout the transcripts based on

Table 1 Interview guide

Questions
- How do you provide physical activity counselling to patients?
- How often do you counsel patients about physical activity?
- To what type of patients do you provide physical activity counselling?
-What do you think about written physical activity prescriptions?
-What reasons make you provide physical activity counselling?
-What are barriers to physical activity counselling?
patients?


study objectives. Initial codes were merged to form initial thematic maps. Subsequently, the researchers defined and named final themes. The researchers compared analytical similarities and differences. A third researcher (SW) was involved in consensus to resolve any differences in data analysis. Themes and quotations were translated from Thai to English by one of the researchers (AW) at the time of manuscript writing, and all researchers approved the translation.

\section{Ethical approval}

This study was approved by the Human Research Ethics Committee of Walailak University (protocol number WUEC-16-006-01). All participants voluntarily took part in this study and provided written informed consent.

\section{Results}

We conducted 17 IDIs in 6 hospitals and reached the point of data saturation, when there was enough information and no emerging idea was expressed. Eleven participants (64.7\%) were female physicians. The mean age of participants was $29.8 \pm 3.4$ years. Most participants $(94.1 \%, n=16)$ had less than 10 years of experience in clinical practice as GPs. Participants had $56.2 \pm 14.1$ outpatients per day and reported an average consultation time of $3.8 \pm 1.8 \mathrm{~min}$ per patient. Table 2 shows participant codes and characteristics. Findings comprised four emerging themes: (i) PA counselling practices; (ii) reasons for PA counselling; (iii) barriers to PA counselling; and (iv) recommendations concerning PA counselling (Fig. 1).

\section{Theme 1: PA counselling practices Focusing on NCDs}

According to PA counselling practice, physicians focused on patients with NCDs including hypertension, diabetes mellitus and dyslipidaemia. Patients with poorly controlled conditions were a target group for PA counselling intervention. The rate of PA counselling in patients with NCDs varied among physicians from $10 \%$ to almost $100 \%$ of cases.

I focus on high-risk patients: obese and overweight. I advise weight reduction, exercise and eating habits. I often talk with obese, chronically ill and other NCD (diabetes, hypertension, and hyperlipidaemia) patients.'

\section{P1, 6-year-experienced, 50 patients/day}

'Look at blood pressure! If the blood pressure is not good or the sugar level is poorly controlled, I will ask about diet control and exercise. For well controlled patients, I do not ask (about diet control and exercise) because I am in a hurry.'

Table 2 Participant codes and characteristics $(n=17)$

\begin{tabular}{|c|c|c|c|c|c|}
\hline Participant code & Gender & Range of age (year) ${ }^{a}$ & Clinical experience (year) & $\begin{array}{l}\text { Average number of } \\
\text { patients per day }\end{array}$ & $\begin{array}{l}\text { Average time for } \\
\text { each consultation (min) }\end{array}$ \\
\hline P1 & Male & $31-35$ & 6 & 50 & 5 \\
\hline P2 & Female & $26-30$ & 2 & 70 & 5 \\
\hline P3 & Male & $31-35$ & 9 & 60 & 3 \\
\hline P4 & Female & $31-35$ & 6 & 80 & 3 \\
\hline P5 & Male & $26-30$ & 6 & 50 & 6 \\
\hline P6 & Female & $26-30$ & 5 & 50 & 2 \\
\hline P7 & Male & $26-30$ & 3 & 35 & 3 \\
\hline P8 & Female & $36-40$ & 12 & 50 & 1 \\
\hline P9 & Female & $26-30$ & 4 & 60 & 3 \\
\hline P10 & Female & $36-40$ & 7 & 80 & 5 \\
\hline P11 & Female & $26-30$ & 3 & 40 & 8 \\
\hline P12 & Male & $26-30$ & 4 & 50 & 1 \\
\hline P13 & Female & $26-30$ & 2 & 60 & 2 \\
\hline P14 & Female & $26-30$ & 4 & 70 & 4 \\
\hline P15 & Female & $26-30$ & 3 & 30 & 5 \\
\hline P16 & Male & $26-30$ & 2 & 60 & 4 \\
\hline P17 & Female & $26-30$ & 2 & 60 & 5 \\
\hline Mean (SD) & & $29.8(3.4)$ & $4.7(2.9)$ & $56.2(14.1)$ & $3.8(1.8)$ \\
\hline
\end{tabular}

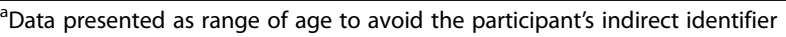




\begin{tabular}{|l|l|}
\hline Theme 1: Physical activity counselling practices \\
$\begin{array}{l}\text { Focusing on NCDs } \\
\text { Using the word 'exercise' instead of 'physical activity' } \\
\text { Components of physical activity counselling }\end{array}$ \\
$\begin{array}{l}\text { Theme 2: Reasons for physical activity counselling } \\
\text { Physical activity as a remedy for NCDs }\end{array}$ \\
$\begin{array}{l}\text { Theme 3: Barriers to physical activity counselling } \\
\text { Lack of knowledge and skills } \\
\text { Discontinuity of care }\end{array}$ \\
Theme 4: Recommendations concerning physical activity counselling \\
Training in physical activity counselling \\
Physical activity prescription: a novel approach \\
Development of health care professionals
\end{tabular}

\section{P15, 3-year-experienced, 30 patients/day}

Musculoskeletal disorders were the second most common focus; physicians advised exercise for patients with musculoskeletal disorders.

I talk to patients with knee osteoarthritis, muscle strain or postural imbalances due to their occupations. I will advise to exercise.'

P8, 12-year-experienced, 50 patients/day

\section{Using the word 'exercise' instead of 'physical activity'}

Physicians used the word 'exercise' to communicate with patients. The Thai term for PA was unfamiliar to many patients. Physicians emphasised that occupational PA could not substitute for leisure or recreational PA.

'I use the word "exercise" to communicate with patients. It is easier to understand. I ask patients about their exercise or activities at home.'

\section{P5, 6-year-experienced, 50 patients/day}

'Most patients think exercise and (outdoor) work are the same. I explain that they are different. Even if it (outdoor work) tires you, it is not comparable (with exercise). Exercise can stimulate neurotransmitters. It is absolutely different. I tell patients about this.'

\section{P11, 3-year-experienced, 40 patients/day}

\section{Components of PA counselling}

GPs counselled patients to participate in PA according to the FITT mnemonic (frequency, intensity, time, and type). Time ( $\mathrm{min} /$ day) and frequency (times/week) of PA were essential information shared with patients. Sometimes, physicians recommended a specific type of PA to patients.

'Walk or jog around your neighbourhoods for 30 minutes at least 3 times a week'

\section{P12, 4-year-experienced, 40 patients/day}

However, the intensity of PA was rarely discussed with patients. When physicians did inform about intensity, they asked patients to palpate their pulses, feel their heartbeats or otherwise detect their exhaustion.

It is hard to communicate the term "moderateintensity" to patients. I tell them to feel tired or sweat. Just 30 minutes of exercise is enough; do not be extremely exhausted.'

\section{P12, 4-year-experienced, 40 patients/day}

\section{Theme 2: reasons for PA counselling} $P A$ for health and quality of life

Physicians could motivate patients to exercise by providing credible information. If patients were physically active, their health and quality of life would be affected for the better.

'There is no financial cost. If patients simply increase their physical activity, it will be beneficial to them. We 
do not have to invest financially. On the contrary, a drug costs money. It is a good reason to tell patients about the benefits of exercise or physical activity.'

\section{P11, 3-year-experienced, 40 patients/day}

\section{$P A$ as a remedy for NCDs}

Physicians counselled patients to increase PA, apart from prescribing medications and advising diet control, when seeing patients with NCDs.

'Treatment does not only involve using drugs. There is a need to collaborate between doctors and patients. As a doctor, I prescribe drugs for my patients and they take them home. They continue to depend on pharmacotherapy. Unless they control their eating habits and exercise, their health will not improve. From my experience, patients who take prescribed drugs while also eating healthily and exercising frequently will experience positive outcomes.'

P4, 6-year-experienced, 80 patients/day

\section{Theme 3: barriers to PA counselling \\ Time constraints}

Time constraints hinder PA counselling due to the large number of patients seen by physicians.

'The limitation is time. We have to accept that we have only 1-2 minutes for each patient.'

P8, 12-year-experienced, 50 patients/day

\section{Lack of knowledge and skills}

Physicians had insufficient knowledge regarding general PA guidelines as well as those for people with diseases. Moreover, communication skills for PA counselling were also insufficient.

If doctors have good communication skills, it will lead to good results. It is not simply telling patients to "go exercise"'

\section{P2, 2-year-experienced, 70 patients/day}

It is about knowledge. I am not sure whether I can choose an appropriate exercise regimen for the patient with a particular disease.'

\section{P11, 3-year-experienced, 40 patients/day}

\section{Discontinuity of care}

Physicians could not follow PA patterns of many patients. Follow-ups were arranged randomly. Therefore, patients did not see a regular physician.

'Actually, patients want to see a regular doctor for the continuity of care. Our system does not support this. Each doctor has his own schedule. I cannot guarantee that a patient will see the same doctor every time.'

P14, 4-year-experienced, 70 patients/day

\section{Theme 4: recommendations concerning PA counselling Training in PA counselling}

Training was intended to improve physician practices. Training in PA counselling should be included in medical education curricula or continuing professional development through meetings, knowledge-sharing activities or workshops.

It needs time to change; perhaps 5, 10 or 20 years. Maybe, it should be started from medical school. If medical students see their seniors prescribing exercise, it can be an "organisational culture". Medical students will learn and follow this pattern and practice. If we want to change, we should begin from medical schools.'

\section{P1, 6-year-experienced, 50 patients/day}

'For practitioners, there is a need to improve knowledge. Therefore, training can be a half-day or one-day course, meeting or conference.'

P5, 6-year-experienced, 50 patients/day

\section{PA prescription: a novel approach}

No GPs included in our study had ever heard about a written prescription ordering PA. Such an intervention could be a promising method to improve the effectiveness of PA counselling. However, PA prescriptions may encounter limitations, such as low literacy levels and communication problems, especially in the Thai context.

'Physical activity prescriptions have both advantages and disadvantages. It is good to overcome some time constraints this way. When patients go home, they can read the prescription. It is, however, a problem that some patients are illiterate. Many senior people in rural areas cannot see text clearly or cannot read. Sometimes, they do not understand what the doctor 
writes or they are not able to follow the prescription. I think this is a major drawback.'

\section{P16, 2-year-experienced, 60 patients/day}

\section{Development of healthcare professionals}

Healthcare providers including nurses, physiotherapists and other exercise specialists could support physicians in PA counselling. Accordingly, there was a need to train such staff to be competent in PA counselling as well as being familiar with the practices involved.

'We need a multidisciplinary team. It is a priority. We should include one person from each health profession. Then, training should be provided. Health professions should communicate (about physical activity) in the same way.'

\section{P3, 9-year-experienced, 60 patients/day}

\section{Discussion}

The GPs emphasised PA in patients with poorly controlled NCDs. They used the word 'exercise' in Thai and often discussed time and frequency of exercise. PA was considered a non-pharmacological treatment for NCDs, which improved health and quality of life. Time constraints, insufficient knowledge of PA guidelines and lack of opportunities to follow-up previously seen patients were barriers to PA counselling among GPs. GPs expressed that training in PA counselling was a priority. Written PA prescriptions may be a promising tool in encouraging patients to increase PA levels. In addition, healthcare providers should be trained to support PA counselling in the clinical setting.

GPs in this study expressed that they viewed PA counselling as vital in the management of NCDs. However, counselling might not be enough to effectively improve PA in a poorly controlled group. PA provided several health benefits to patients with symptomatic diseases; moreover, it was important in primary prevention and reduction in disease burden [29]. A worldwide campaign regarding promotion of PA in clinical settings, 'Exercise is Medicine', set a goal to make PA assessment and exercise prescription a standard in prevention and treatment of diseases for all patients [30]. Additionally, a systematic review revealed that a majority of primary care providers believed PA promotion was important for all patients [21].

According to our findings, physicians did not use the description of PA to communicate with patients, as it is not a familiar term in the Thai language. Exercise, however, is a common word used interchangeably with PA
[31]. Physicians in this study expressed that exercise was a structured and repetitive activity that aimed to improve physical fitness and functions. Hence, occupational PA, characterised by lower exercise intensity and insufficient recovery [32], should not be included when describing PA for clinical treatment purposes. The FITT mnemonic has been commonly used in clinical settings and studies [33-36]. Physicians that participated in this study also applied FITT to counsel about PA. However, the intensity of PA was infrequently discussed with patients. The avoidance of counselling patients for exercise intensity was likely due to time constraints faced by GPs. This gap is very important because the intensity of PA is a main indicator of cardiometabolic benefits [37]. GPs should address this concern and find out an approach to communicate about PA intensity to their patients. One approach is to provide clearer guidance on selfdetermined PA intensity [38]. The talk test can be a method, which is practical, valid, reliable and inexpensive, to fill such a gap in clinical settings [39-41]. Alternatively, GPs can use the Compendium of Physical Activities, which provides energy expenditure of each PA as a reference to advise patients to participate in any preferred moderate- to vigorous-intensity PA [42].

Physicians in this study had only 3.8 min per consultation. A study conducted in the USA revealed that $75 \%$ of primary care providers spend 3-6 min on PA counselling [43]. Considering an average 20-min consultation in America [44], this proportion seems reasonable. However, limited consultation time is a major challenge in Thailand, as a lack of time to counsel patients remains a major problem among primary care providers in different settings $[21,45]$. Our findings revealed that insufficient knowledge and lack of skills were also barriers in counselling patients. These findings were consistent with those evaluating primary care providers in other countries $[21,45]$. Although training in PA is essential, it may not have received an emphasis in medical school curricula. Previous studies reported that a small amount of time was spent teaching PA in the UK (4.2 h) [46], US (8.1 h) [47] and Australia (12.3 h) [48]. A lack of care continuity led to skipping PA counselling altogether as physicians could not receive feedback from their patients [49].

GPs expressed that training in PA counselling during undergraduate medical education and continuing professional development could be effective. Several studies reported that undergraduate, postgraduate and continuing professional development courses contributed to positive outcomes of knowledge, skills and attitudes regarding PA counselling [50-53]. PA prescription, however, was a new tool of questionable utility to support PA counselling according to study participants. Evidence clearly supported the capacity of PA prescriptions to positively 
affect patient exercise behaviours and improve metabolic risk factors [54-56]. However, PA prescriptions were considered a questionable modality due to a lack of education in non-pharmaceutical therapy, which reflected that applying PA prescription alone could not ensure its effectiveness [57, 58]. Participating GPs expressed a need to develop multidisciplinary teams to improve the quality of PA counselling. A similar approach, which promoted teamwork among multidisciplinary healthcare professionals, was recommended as an effective method to implement in primary care [59-61].

This qualitative study was conducted in several district hospitals and represented a wide diversity of therapeutic and administrative practices among physicians in different primary care settings. Results included recommendations regarding PA counselling, which were analysed from the perspectives of GPs in real settings. The results could support the understanding of general practice rather than practice in a particular setting. There were two limitations of the study. First, as the participants recruited were early career GPs (aged 26-37 years) from district hospitals, understanding practices of physicians in other age groups remains unclear. Most young GPs are mandated to work at district hospitals prior to specialisation, and we did not contact more experienced physicians for participation in our study. The results might not represent the current practice of mid-career or senior GPs. Second, the qualitative approach we employed may not have yielded results applicable to other physicians in varying practice settings.

\section{Recommendations}

There is a need to improve the quality of PA counselling. As mentioned previously, training in PA is sparse in medical education, especially, PA counselling [62]. Training programmes should be constructed to overcome the important barriers in clinical practice - lack of knowledge and time constraints [63]. Although developing a tool such as a written PA prescription may improve and facilitate PA counselling, GPs may require more time to complete the task. Alternatively, using a PA prescription proforma which used pictures and symbols rather than words may convey the necessary information for illiterate patients or patients with communication difficulties. Therefore, using an effective tool together with a comprehensive model is needed. An example model consists of three steps: PA assessment, counselling and/or PA prescription, and referral to experts [64]. According to this model, GPs have to work with multidisciplinary teams. This approach can help GPs deal with the time constraints in their practices. Maintaining the continuity of care is another element to change patients' PA behaviours. A systemic structure in healthcare services is required to continue the use of information, the consistent and coherent management, and the ongoing therapeutic relationship [65]. The welldesigned system to maintain the continuity of care may compensate the lack of opportunity to see the same physician.

\section{Conclusions}

GPs included in this study expressed that PA counselling is essential in the treatment of NCDs. Counselling should focus on improving exercise in patients with poorly controlled conditions. Improving the quality of PA counselling in primary care needs 3 Ts: training, tools, and teams. GPs recommend initiating widespread training in PA counselling, application of tools for prescribing PA and ample multidisciplinary collaboration across healthcare fields. Implementing use of written PA prescriptions may encourage patients to increase PA. Multidisciplinary teams should be developed to support PA counselling in the clinical setting. Further studies should focus on appropriate techniques to implement PA counselling in clinical settings and overcome existing barriers.

\section{Abbreviations}

FITT: Frequency, intensity, time, and type; GPs: General practitioners; IDIs: Indepth interviews; NCDs: Non-communicable diseases; PA: Physical activity; SD: Standard deviation; UK: United Kingdom; US: United States; USA: United States of America; WHO: World Health Organization

\section{Acknowledgments}

We would like to thank the Physical Activity Research Centre for their support in conducting this study and all participants for their contribution.

\section{Authors' contributions}

AW and ST developed the study design. AW conducted all in-depth interviews. AW, ST, and SW contributed to data analysis. AW and ST wrote the first draft of the manuscript. All authors approved the final manuscript.

\section{Funding}

This work was supported by the Physical Activity Research Centre, Thai Health Promotion Foundation [grant number 60-00-01]. The funding body had no role in the design, execution, interpretation, or writing of the study.

Availability of data and materials

Data used during the study are available from the corresponding author on reasonable request.

\section{Ethics approval and consent to participate}

This study was approved by the Human Research Ethics Committee of Walailak University (protocol number: WUEC-16-006-01). All participants voluntarily took part in this study and provided written informed consent.

\section{Consent for publication}

Not applicable.

\section{Competing interests}

The authors declare that they have no competing interests.

\section{Author details}

'School of Medicine, Walailak University, Thasala, Nakhon Si Thammarat 80161, Thailand. 'Walailak University Hospital, Thasala, Nakhon Si Thammarat 80161, Thailand. ${ }^{3}$ Thasala Hospital, Thasala, Nakhon Si Thammarat 80160, Thailand. ${ }^{4}$ Department of Orthopedic Surgery and Physical Medicine, Faculty of Medicine, Prince of Songkla University, Hat Yai, Songkhla 90110, Thailand. 
Received: 1 October 2018 Accepted: 23 May 2019

\section{Published online: 29 May 2019}

\section{References}

1. World Health Organization. Deaths from NCDs. http://www.who.int/gho/ ncd/mortality_morbidity/ncd_total_text/en/. Accessed 10 Nov 2017.

2. World Health Organization. 10 facts on noncommunicable diseases 2013 http://www.who.int/features/factfiles/noncommunicable_diseases/en/. Accessed 10 Nov 2017

3. Ding D, Lawson KD, Kolbe-Alexander TL, Finkelstein EA, Katzmarzyk PT, van Mechelen W, et al. The economic burden of physical inactivity: a global analysis of major non-communicable diseases. Lancet. 2016;388(10051): 1311-24.

4. GBD 2017 Risk Factor Collaborators. Global, regional, and national comparative risk assessment of 84 behavioural, environmental and occupational, and metabolic risks or clusters of risks for 195 countries and territories, 1990-2017: a systematic analysis for the Global Burden of Disease Study 2017. Lancet. 2018;392(10159):1923-94.

5. World Health Organization. Global status report on noncommunicable diseases 2014. Geneva, Switzerland: World Health Organization; 2014.

6. Wattanapisit A. A review of the current international physical activity guidelines for various age groups to prevent and control noncommunicable diseases. Songkla Med J. 2016;34:39-49.

7. World Health Organization. Global recommendations on physical activity for health. Geneva, Switzerland: World Health Organization; 2010.

8. Elley CR, Kerse N, Arroll B, Robinson E. Effectiveness of counselling patients on physical activity in general practice: cluster randomised controlled trial. BMJ. 2003;326:793.

9. Grandes G, Sanchez A, Sanchez-Pinilla R, Torcal J, Montoya I, Lizarraga K, et al. Effectiveness of physical activity advice and prescription by physicians in routine primary care: a cluster randomized trial. Arch Intern Med. 2009;169(7):694-701.

10. Meriwether RA, Lee JA, Lafleur AS, Wiseman P. Physical activity counseling. Am Fam Physician. 2008;77:1129-36.

11. The Writing Group for the Activity Counseling Trial Research Group. Effects of physical activity counseling in primary care: the activity counseling trial: a randomized controlled trial. JAMA. 2001;286:677-87.

12. Orrow G, Kinmonth AL, Sanderson S, Sutton S. Effectiveness of physical activity promotion based in primary care: systematic review and metaanalysis of randomised controlled trials. BMJ. 2012;344:e1389.

13. Stead LF, Buitrago D, Preciado N, Sanchez G, Hartmann-Boyce J, Lancaster T. Physician advice for smoking cessation. Cochrane Database Syst Rev. 2013; (31, 5):CD000165.

14. Global Advocacy for Physical Activity (GAPA) the Advocacy Council of the International Society for Physical Activity and Health (ISPAH). In: NCD prevention: investments that work for physical activity; 2011. http://www. globalpa.org.uk/pdf/investments-work.pdf. Accessed 12 Nov 2017.

15. Schiphorst C, Murray A, Kelly P, Oliver C, Bull F. Infographic. Best investments for physical activity. Br J Sports Med. 2017;51:1175.

16. Vuori IM, Lavie CJ, Blair SN. Physical activity promotion in the health care system. Mayo Clin Proc. 2013;88:1446-61.

17. Bélanger M, Couturier E, Dion N, Girouard V, Phillips J, Brunet J. Family physicians' perceptions toward writing physical activity prescriptions: I tell patients it's like the super pill! Qual Prim Care. 2015;23:113-21.

18. Phillips EM, Kennedy MA. The exercise prescription: a tool to improve physical activity. PM R 2012;4:818-825

19. Gagliardi AR, Abdallah F, Faulkner G, Ciliska D, Hicks A. Factors contributing to the effectiveness of physical activity counselling in primary care: a realist systematic review. Patient Educ Couns. 2015;98(4):412-9.

20. Shuval K, Leonard T, Drope J, Katz DL, Patel AV, Maitin-Shepard M, et al. Physical activity counseling in primary care: insights from public health and behavioral economics. CA Cancer J Clin. 2017;67(3):233-44.

21. Hebert ET, Caughy MO, Shuval K. Primary care providers' perceptions of physical activity counselling in a clinical setting: a systematic review. $\mathrm{Br}$ J Sports Med. 2012;46:625-31.

22. Breckon JD, Johnston LH, Hutchison A. Physical activity counseling content and competency: a systematic review. J Phys Act Health. 2008;5:398-417.

23. The medical Council of Thailand. Medical competency assessment criteria for National Licnse; 2012

24. Wattanapisit A, Saengow U. Patients' perspectives regarding hospital visits in the universal health coverage system of Thailand: a qualitative study. Asia Pac Fam Med. 2018;17(9):018-0046.
25. Valerio MA, Rodriguez N, Winkler P, Lopez J, Dennison M, Liang Y, et al. Comparing two sampling methods to engage hard-to-reach communities in research priority setting. BMC Med Res Methodol. 2016;16:146.

26. Saunders B, Sim J, Kingstone T, Baker S, Waterfield J, Bartlam B, et al. Saturation in qualitative research: exploring its conceptualization and operationalization. Qual Quant. 2018;52(4):1893-907.

27. Braun V, Clarke V. Using thematic analysis in psychology. Qual Res Psychol. 2006:3:77-101.

28. Gale NK, Heath G, Cameron E, Rashid S, Redwood S. Using the framework method for the analysis of qualitative data in multi-disciplinary health research. BMC Med Res Methodol. 2013;13:117.

29. Alves AJ, Viana JL, Cavalcante SL, Oliveira NL, Duarte JA, Mota J, et al. Physical activity in primary and secondary prevention of cardiovascular disease: overview updated. World J Cardiol. 2016;8:575-83.

30. Sallis R. Exercise is medicine: a call to action for physicians to assess and prescribe exercise. Phys Sportsmed. 2015;43:22-6.

31. Caspersen CJ, Powell KE, Christenson GM. Physical activity, exercise, and physical fitness: definitions and distinctions for health-related research. Public Health Rep. 1985;100:126-31.

32. Holtermann A, Krause N, van $\operatorname{der}$ Beek AJ, Straker L. The physical activity paradox: six reasons why occupational physical activity (OPA) does not confer the cardiovascular health benefits that leisure time physical activity does. Br J Sports Med. 2018;52(3):149.

33. Beaulac J, Carlson A, Boyd RJ. Counseling on physical activity to promote mental health: practical guidelines for family physicians. Can Fam Physician. 2011:57:399-401.

34. Bohm CJ, Storsley LJ, Hiebert BM, Nelko S, Tangri N, Cheskin LJ, et al. Impact of exercise counseling on physical function in chronic kidney disease: an observational study. Can J Kidney Health Dis. 2018;5 2054358117753615.

35. McInnis KJ, Franklin BA, Rippe JM. Counseling for physical activity in overweight and obese patients. Am Fam Physician. 2003;67:1249-56.

36. Osadnik CR, Rodriques FM, Camillo CA, Loeckx M, Janssens W, Dooms C, et al. Principles of rehabilitation and reactivation. Respiration. 2015;89:2-11.

37. Tarp J, Child A, White T, Westgate K, Bugge A, Grontved A, et al. Physical activity intensity, bout-duration, and cardiometabolic risk markers in children and adolescents. Int J Obes. 2018;42(9):1639-50.

38. Segar M, Taber JM, Patrick H, Thai CL, Oh A. Rethinking physical activity communication: using focus groups to understand women's goals, values, and beliefs to improve public health. BMC Public Health. 2017;17(1):462.

39. Reed JL, Pipe AL. The talk test: a useful tool for prescribing and monitoring exercise intensity. Curr Opin Cardiol. 2014;29:475-80.

40. Reed JL, Pipe AL. Practical approaches to prescribing physical activity and monitoring exercise intensity. Can J Cardiol. 2016;32:514-22.

41. Woltmann ML, Foster C, Porcari JP, Camic CL, Dodge C, Haible S, et al. Evidence that the talk test can be used to regulate exercise intensity. J Strength Cond Res. 2015;29:1248-54.

42. Ainsworth BE, Haskell WL, Herrmann SD, Meckes N, Bassett DR Jr, TudorLocke C, et al. 2011 compendium of physical activities: a second update of codes and MET values. Med Sci Sports Exerc. 2011;43(8):1575-81.

43. Albright CL, Cohen S, Gibbons L, Miller S, Marcus B, Sallis J, et al. Incorporating physical activity advice into primary care: physician-delivered advice within the activity counseling trial. Am J Prev Med. 2000;18:225-34.

44. Irving $G$, Neves AL, Dambha-Miller $H$, Oishi A, Tagashira $H$, Verho A, et al. International variations in primary care physician consultation time: a systematic review of 67 countries. BMJ Open. 2017;7(10):e017902.

45. AuYoung M, Linke SE, Pagoto S, Buman MP, Craft LL, Richardson CR, et al. Integrating physical activity in primary care practice. Am J Med. 2016;129:1022-9.

46. Weiler R, Chew S, Coombs N, Hamer M, Stamatakis E. Physical activity education in the undergraduate curricula of all UK medical schools. Are tomorrow's doctors equipped to follow clinical guidelines? Br J Sports Med. 2012:46:1024.

47. Stoutenberg M, Stasi S, Stamatakis E, Danek D, Dufour T, Trilk JL, et al. Physical activity training in US medical schools: preparing future physicians to engage in primary prevention. Phys Sportsmed. 2015;43:388-94.

48. Strong A, Stoutenberg M, Hobson-Powell A, Hargreaves M, Beeler $H_{\text {, }}$ Stamatakis E. An evaluation of physical activity training in Australian medical school curricula. J Sci Med Sport. 2017;20:534-8.

49. McPhail S, Schippers M. An evolving perspective on physical activity counselling by medical professionals. BMC Fam Pract. 2012;13:31.

50. Arciniegas Calle MC, Lobelo F, Jiménez MA, Páez DC, Cortés S, de Lima A, et al. One-day workshop-based training improves physical activity 
prescription knowledge in Latin American physicians: a pre-test post-test study. BMC Public Health. 2016;16:1224.

51. Dacey ML, Kennedy MA, Polak R, Phillips EM. Physical activity counseling in medical school education: a systematic review. Med Educ Online. 2014;19. https://doi.org/10.3402/meo.v19.24325.

52. Joyce $\mathrm{CL}$, O'Tuathaigh $\mathrm{CM}$. Increased training of general practitioners in Ireland may increase the frequency of exercise counselling in patients with chronic illness: a cross-sectional study. Eur J Gen Pract. 2014;20:314-9.

53. Polak R, Shani M, Dacey M, Tzuk-Onn A, Dagan I, Malatskey L. Family physicians prescribing lifestyle medicine: feasibility of a national training programme. Postgrad Med J. 2016;92:312-7.

54. Lundqvist S, Börjesson M, Larsson MEH, Hagberg L, Cider A. Physical activity on prescription (PAP), in patients with metabolic risk factors. A 6-month follow-up study in primary health care. PLoS One. 2017;12:e0175190.

55. Patel A, Schofield GM, Kolt GS, Keogh JW. General practitioners' views and experiences of counselling for physical activity through the New Zealand green prescription program. BMC Fam Pract. 2011;12:119.

56. Thornton JS, Fremont P, Khan K, Poirier P, Fowles J, Wells GD. Physical activity prescription: a critical opportunity to address a modifiable risk factor for the prevention and management of chronic disease: a position statement by the Canadian Academy of Sport and Exercise Medicine. Clin J Sport Med. 2016;26:259-65.

57. Hallal PC, Lee IM. Prescription of physical activity: an undervalued intervention. Lancet. 2013;381:356-7.

58. Persson G, Brorsson A, Ekvall Hansson E, Troein M, Strandberg EL. Physical activity on prescription (PAP) from the general practitioner's perspective - a qualitative study. BMC Fam Pract. 2013;14:128.

59. Aittasalo M, Kukkonen-Harjula K, Toropainen E, Rinne M, Tokola K, Vasankari T. Developing physical activity counselling in primary care through participatory action approach. BMC Fam Pract. 2016;17:141.

60. Cochrane AJ, Dick B, King NA, Hills AP, Kavanagh DJ. Developing dimensions for a multicomponent multidisciplinary approach to obesity management: a qualitative study. BMC Public Health. 2017;17:814.

61. Verwey $R$, van der Weegen S, Spreeuwenberg M, Tange $H$, van der Weijden $T$, de Witte L. Upgrading physical activity counselling in primary care in the Netherlands. Health Promot Int. 2016;31:344-54.

62. Wattanapisit A, Vijitpongjinda S, Saengow U, Amaek W, Thanamee S, Petchuay P. Results from the medical school physical activity report card (MSPARC) for a Thai medical school: a mixed methods study. BMC Med Educ. 2018;18(1):288.

63. Galaviz Kl, Estabrooks PA, Ulloa EJ, Lee RE, Janssen I, Lopez YTJ, et al. Evaluating the effectiveness of physician counseling to promote physical activity in Mexico: an effectiveness-implementation hybrid study. Transl Behav Med. 2017:7(4):731-40

64. Stoutenberg M, Galaviz KI, Lobelo F, Joy E, Heath GW, Hutber A, et al. A pragmatic application of the RE-AIM framework for evaluating the implementation of physical activity as a standard of care in health systems. Prev Chronic Dis. 2018:10(15):170344.

65. Haggerty IL, Reid RJ, Freeman GK, Starfield BH, Adair CE, McKendry R. Continuity of care: a multidisciplinary review. BMJ. 2003;327(7425):1219-21.

\section{Publisher's Note}

Springer Nature remains neutral with regard to jurisdictional claims in published maps and institutional affiliations.

Ready to submit your research? Choose BMC and benefit from:
- fast, convenient online submission
- thorough peer review by experienced researchers in your field
- rapid publication on acceptance
- support for research data, including large and complex data types
- gold Open Access which fosters wider collaboration and increased citations
- maximum visibility for your research: over 100M website views per year
At BMC, research is always in progress.
Learn more biomedcentral.com/submissions

